\title{
Influence of Post-Earthquake Rainfall on the Stability of Clay Slopes (IPL-192)
}

\author{
Binod Tiwari, Beena Ajmera, and Duc Tran
}

\begin{abstract}
Rainfall and earthquakes are considered two of the major causes of landslides worldwide. These landslides cause billions of dollars in property damage and revenue losses, as well as the deaths of thousands of people each year. While researchers have been examining the effect of either rainfall or earthquakes on the deformation and stability of slopes, the combined effect of rainfall and earthquakes on deformation and slope stability has not been evaluated systematically. In this study, a series of model slopes were constructed in a Plexiglas container placed on top of a shake table. The model slopes were prepared to have different initial void ratios of $0.89,1.0$ and 1.2 and various slope inclinations of $30^{\circ}, 40^{\circ}$, and $45^{\circ}$. These slopes were instrumented with accelerometers, tensiometers and inclinometers and subjected to a number of sinusoidal seismic motions with different seismic accelerations from 0.1 to $0.3 \mathrm{~g}$, with several frequencies ranging from 1 to $3 \mathrm{~Hz}$ for various durations ranging from 10 cycles to 50 cycles of loading. Following the earthquake event, a rain simulator system was used to induce rainfall at intensities of either 18, 30 or $60 \mathrm{~mm} / \mathrm{h}$. The seepage velocity, spatial variation of suction and the deformation of the slopes were determined. The results obtained were compared to those obtained from similar slopes subjected to rainfall without an earthquake event. The study showed that the seismic shaking resulted in a reduction in the seepage velocity in the slope, which led to an increase in the factor of safety of the slope with time.
\end{abstract}

\section{Keywords}

Earthquake-induced landslides - Rainfall-induced landslides - Partially saturated soils • Shake table $\cdot$ Seepage velocity

\section{B. Tiwari}

Department of Civil and Environmental Engineering, California State University Fullerton, $800^{\circ}$ N. State College Blvd.E-419, Fullerton, CA 92831, USA

e-mail: btiwari@fullerton.edu

\section{B. Ajmera $(\square)$}

California State University Fullerton, $800^{\circ}$ N. State College Blvd. E-318, Fullerton, CA 92831, USA

e-mail: bajmera@fullerton.edu

\section{Tran}

Department of Civil and Environmental Engineering, Graduate Student California State University Fullerton, $800^{\circ}$ N. State College Blvd, Fullerton, CA 92831, USA

e-mail: ductran@csu.fullerton.edu

\section{Introduction}

Globally, rainfall and earthquakes are two of the most prominent causes of landslides, which result in thousands of injuries and deaths, and billions of dollars of property damage and revenue losses each year. In recent history, the 2014 Oso Landslide in Washington, which was said to be triggered by heavy rainfall, is among the worst landslide disasters in the United States (Keaton et al. 2014; Iverson et al. 2015). Researchers, including Tiwari et al. (2016), Tran (2016), Collins and Znidarcic (2004), Kim et al. (2012), Orense et al. (2004), Ling and Ling (2012), Lu et al. 
(2012), and Tiwari and Caballero (2015), have studied the effect of various parameters such as slope geometry, soil density, and intensity of rainfall on the stability of rainfall-induced slope failures. Furthermore, databases containing over 3400 landslides after the 2011 Tohoku Earthquake in Japan (Wartman et al. 2013), over 14,000 landslides after the 2015 Gorkha Earthquake in Nepal (Tiwari et al. 2016), over 56,000 landslides after the 2008 Wenchuan Earthquake in China (Dai et al. 2011) and over 10,000 landslides after the 1999 Chi-Chi Earthquake in Taiwan (Khazai and Sitar 2004) clearly demonstrated the disastrous consequences of earthquake-induced landslides. Following strong ground shaking, a major concern for residents and the local officials in the region is the potential damage and consequences that could result if additional landslides are triggered during the future rainstorms and monsoon seasons. Despite this, there has been little research geared at understanding the influence of post-earthquake rainfall on the stability of slopes. This study aims to fill that gap by examining the effect of rainfall and seismic shaking on model soil slopes and numerical simulations using the GeoStudio software suite.

The soil used in the model soil slopes was collected from a housing development project in Mission Viejo, California. At this project site, slope movements were reported to have occurred on January 20, 2005 near the residences on Encorvardo Lane on the eastern side of Ferrocarril. Heavy rainfall from December 28, 2004 through January 11, 2005 resulted in almost $254 \mathrm{~mm}$ of precipitation. It was following this storm that initial movements were recorded on a $70 \mathrm{ft}$ tall graded slope constructed in 1967. Model soil slopes tested in this study were prepared from compacted fill slope material obtained from this housing development project. Several standard laboratory tests were also conducted to determine the material properties. This paper will detail the influence of post-earthquake rainfall on the stability of slopes by presenting the results of the model soil slopes and the numerical simulations conducted.

\section{Materials and Methods}

The soil used in this study was collected from the housing development project in Mission Viejo, California. It was used to measure the grain size distribution (ASTM D422), the index properties (ASTM D4318), maximum dry density and the optimum moisture content (ASTM D1557), the saturated coefficients of permeability (ASTM D5084), the soil water characteristic curve and the shear strength parameters (ASTM D3080). Table 1 outlines the material properties for the soil properties.

The slope was constructed in a $1.2 \mathrm{~m} \times 1.2 \mathrm{~m} \times 1.2 \mathrm{~m}$ Plexiglas container mounted on a shake table. At the bottom of the container, a drainage layer consisting of a 5-cm-thick gravel layer and perforated plastic pipe drainage network were installed. To prevent the soil from clogging the drainage layer and the perforated pipe, a geo-textile was placed on top of the gravel drainage layer. The soil used to construct the model slopes was first sieved through a \#40 sieve using a mechanical shaker and mixed with sufficient water to have an initial moisture content of $12 \%$, corresponding to the field moisture content. The soil was placed in $5 \mathrm{~cm}$ thick lifts compacted to a void ratio of 1.2 to create a slope inclined at $40^{\circ}$. The completed model slope is pictured in Fig. 1.

Tensiometers and accelerometers were installed at various locations and depths (Figs. 2 and 3) within the slope to instrument the slope in order to measure the pore water pressure during the seismic loading and the post-earthquake rainfall event. Decagon T5 tensiometers with an active surface area of $0.5 \mathrm{~cm}^{2}$ and a $5 \mathrm{~mm}$ diameter ceramic tip were used in this study. They are capable of recording pore water pressures ranging from +100 to $-85 \mathrm{kPa}$. The holes made to install the tensiometers were backfilled with the slope material and the surface was covered with a bentonite slurry to prevent preferential movement of water through those locations.

The slope was then subjected to different ground motions using the shake table at California State University, Fullerton. The $1.5 \mathrm{~m} \times 2 \mathrm{~m}$ shake table uses a $25 \mathrm{kN}$ actuator and has a $\pm 6.5 \mathrm{~cm}$ horizontal capacity. The model slope was subjected to sinusoidal motions with accelerations ranging in amplitude from $0.1 \mathrm{~g}$ to $0.3 \mathrm{~g}$ with frequencies between 1 and $3 \mathrm{~Hz}$. Each motion was applied for 10 to 50 cycles of loading. The ground motion recorded at Station 90095 during the 1994 Northridge Earthquake was also applied to the slope model. The ground motions applied are shown in Fig. 4. Following the seismic loading, a rain simulator system was placed on top of the slope. The system was used to apply rainfall at an intensity of $3.6 \mathrm{~cm} / \mathrm{h}$ until the slope became completely saturated, as determined from the location of the wetting front. A photograph of the rain simulator system applying rainfall to the model slope is presented in Fig. 5.

A second model was prepared following the procedure described above and instrumented as illustrated in Fig. 2. In this model, the slope was subjected to rainfall without any seismic excitation. The results obtained served as baseline in order to compare the effect of the seismic loading on the observed responses.

The slope geometry and material properties were used to perform numerical simulations using the SEEP/W, SIGMA/W, and QUAKE/W modules in the GeoStudio software suite. SEEP/W was used obtain the pore-water pressure distribution. The seismic loading was simulated using QUAKE/W, in which the input motion was the same as that used in the experimental models, as shown in Fig. 4. 
Table 1 Soil properties

\begin{tabular}{|c|c|}
\hline Property & Value \\
\hline Gravel $(\%)$ & 0 \\
\hline Sand $(\%)$ & 15 \\
\hline Silt (\%) & 65 \\
\hline Clay $(\%)$ & 20 \\
\hline Liquid Limit (\%) & 57 \\
\hline Plasticity Index (\%) & 30 \\
\hline USCS Classification & $\mathrm{CH}$ \\
\hline Maximum Dry Density (pcf) & 110 \\
\hline Optimum Moisture Content (\%) & 15 \\
\hline $\begin{array}{l}\text { Saturated permeability at }(\mathrm{m} / \mathrm{s}) \\
\text { Void ratio of } 0.89 \\
\text { Void ratio of } 1.00 \\
\text { Void ratio of } 1.20\end{array}$ & $\begin{array}{l}4 \times 10^{-9} \\
5 \times 10^{-9} \\
9 \times 10^{-9}\end{array}$ \\
\hline $\begin{array}{l}\text { Friction angle }\left(^{\circ}\right) \text { and cohesion }(\mathrm{kPa}) \text { at void ratio of } 1.2 \text { at } \\
\text { Degree of Saturation of } 33 \% \\
\text { Degree of Saturation of } 100 \%\end{array}$ & $\begin{array}{l}27^{\circ}, 34 \mathrm{kPa} \\
26^{\circ}, 0 \mathrm{kPa}\end{array}$ \\
\hline Rate of increase in shear strength relative to matric suction & $27.2^{\circ}$ \\
\hline
\end{tabular}

Fig. 1 Slope model used in this study

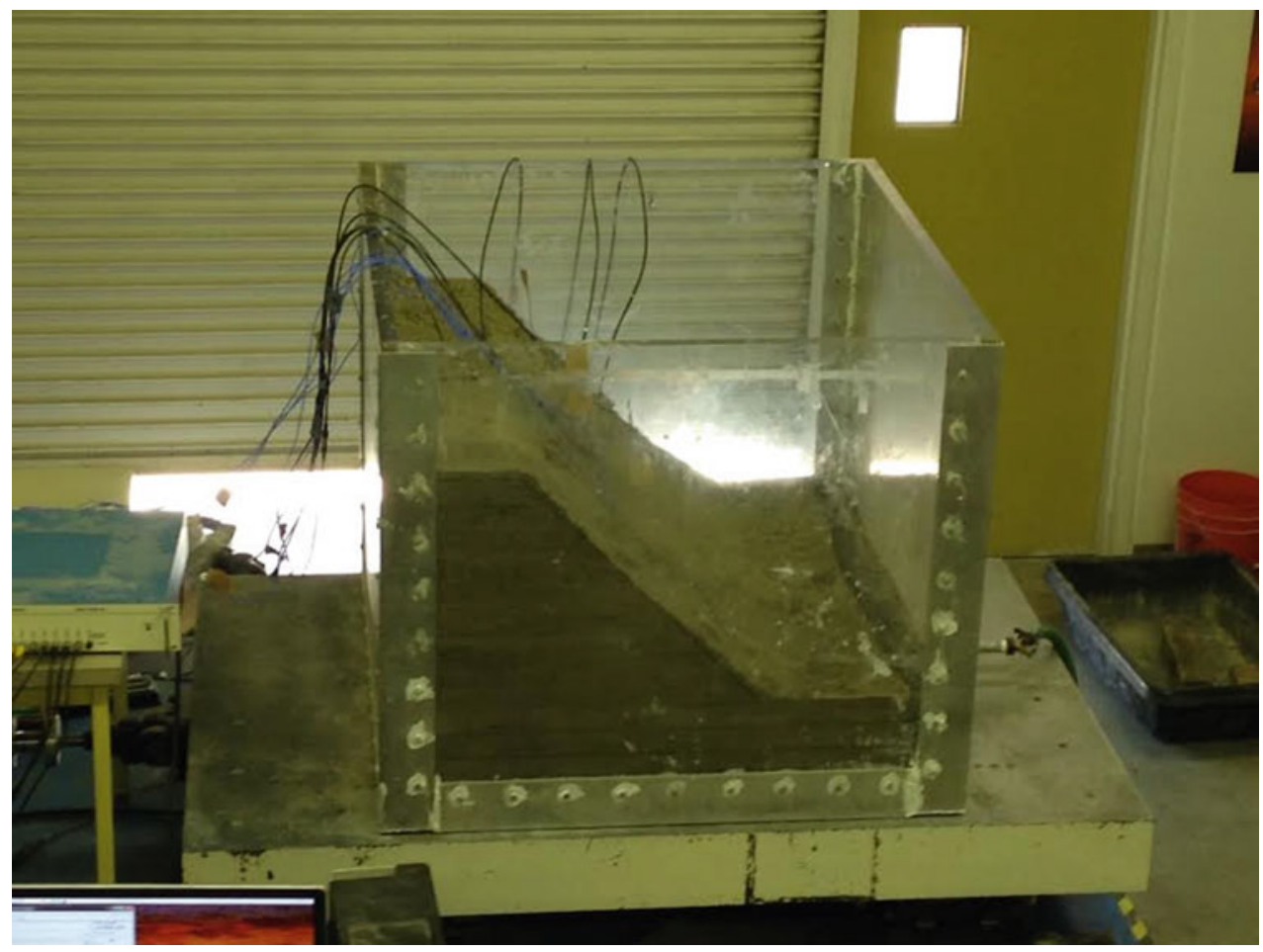

The seepage patterns as a result of the rainfall were simulated using SIGMA/W.

\section{Results and Discussion}

The movement of the wetting fronts with time for the two models prepared in the laboratory that were subjected to post-earthquake rainfall and to rainfall without earthquake shaking are compared and presented in Fig. 6. The locations of the tensiometers, denoted by $\mathrm{T}$, are also shown in this figure. Unfortunately, all except one of the tensiometers malfunctioned in the slope model that was subjected to rainfall without any shaking (Fig. 6b). Figure 6 also contains the values of the seepage velocity computed, based on the time required for the wetting front to reach Point A. It is clear from Fig. 6 that more time was required for the complete saturation of the model that was subjected to 
Fig. 2 Locations of tensiometers

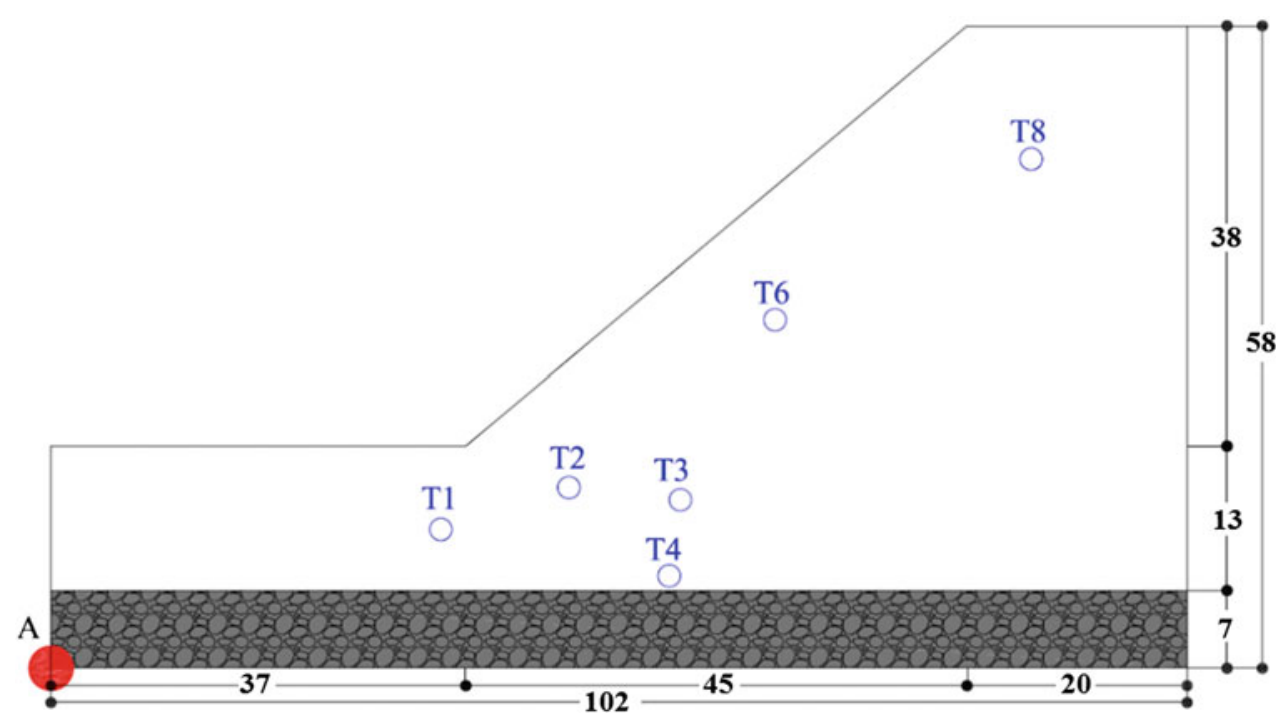

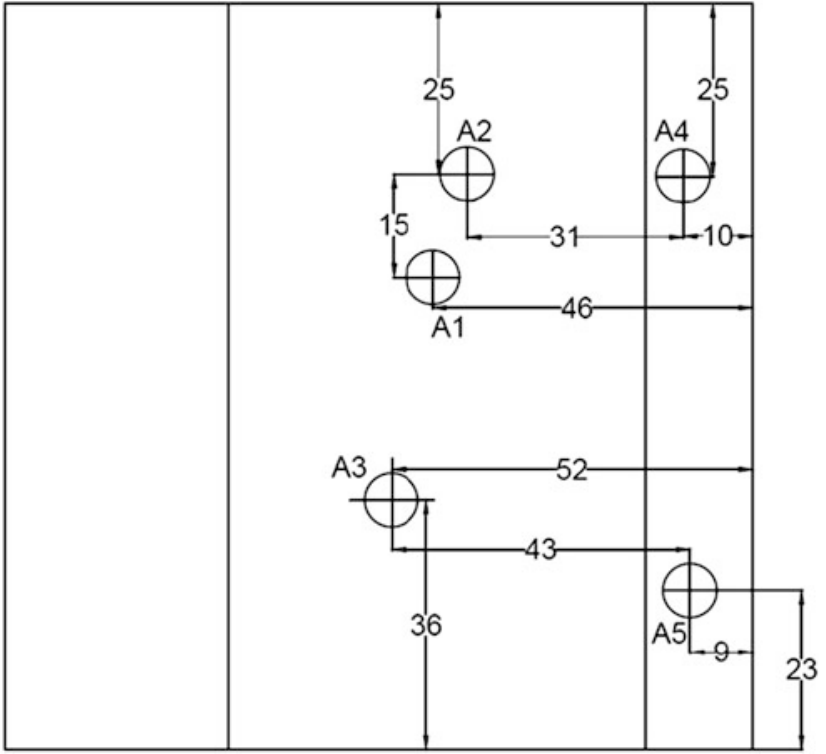

Fig. 3 Plan view of slope showing locations of the accelerometers

earthquake loading than the time required for complete saturation of the model that was not subjected to any shaking. Specifically, the seepage velocity in the slope subjected to post-earthquake rainfall was $14.6 \mathrm{~cm} / \mathrm{h}$ in comparison to the seepage velocity of $25.7 \mathrm{~cm} / \mathrm{h}$ in the slope subjected to rainfall without earthquake loading. A comparison of the results from the tensiometers (Fig. 7) also agrees with the observations made of the wetting fronts. Specifically, the results show that approximately $2.7 \mathrm{~h}$ were required for the suction to reduce to a value of zero at the location of $\mathrm{T} 1$ in the slope subjected to rainfall without earthquake loading, while approximately $3.2 \mathrm{~h}$ were required in the slope subjected to post-earthquake rainfall.

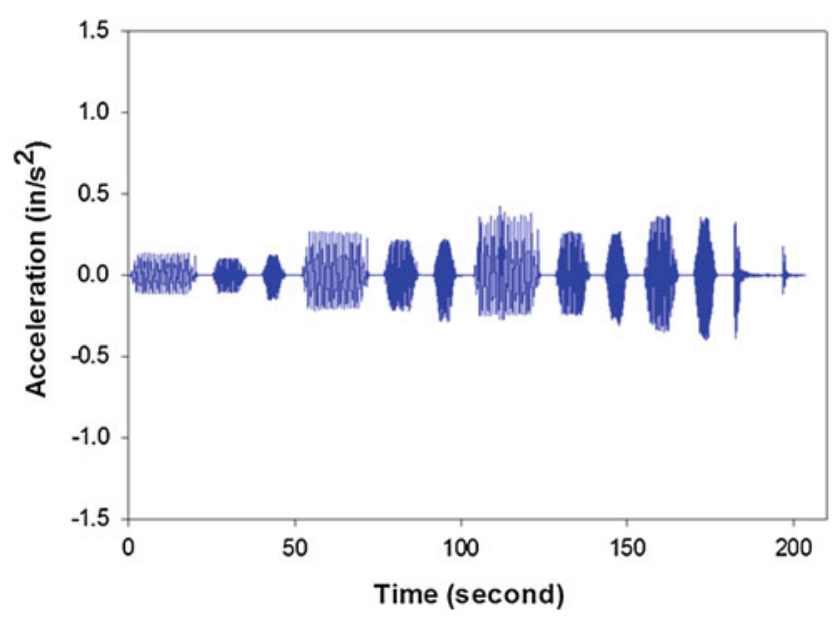

Fig. 4 Applied cyclic loading

\section{Results from Numerical Simulations}

Figure 8 shows the movement of the wetting front with time obtained from the numerical simulations conducted as part of this study. The results in Fig. 8 were used to calculate the seepage velocity to point $\mathrm{A}$ and compared with the experiment results. As it can be observed from Fig. 6b and Fig. 8, the seepage velocity from the numerical simulations are similar to those obtained from the experimental models.

SLOPE/W was used to calculate the factor of safety of the slope subjected to post-earthquake rainfall. The variation in the factor of safety during the earthquake loading is presented in Fig. 9, while the results for the factor of safety during the post-earthquake rainfall are presented in Fig. 10. Figure 10 also contains the results for the factor of safety for the slope subjected to rainfall without any earthquake loading. The figure shows that the factor of safety for the 


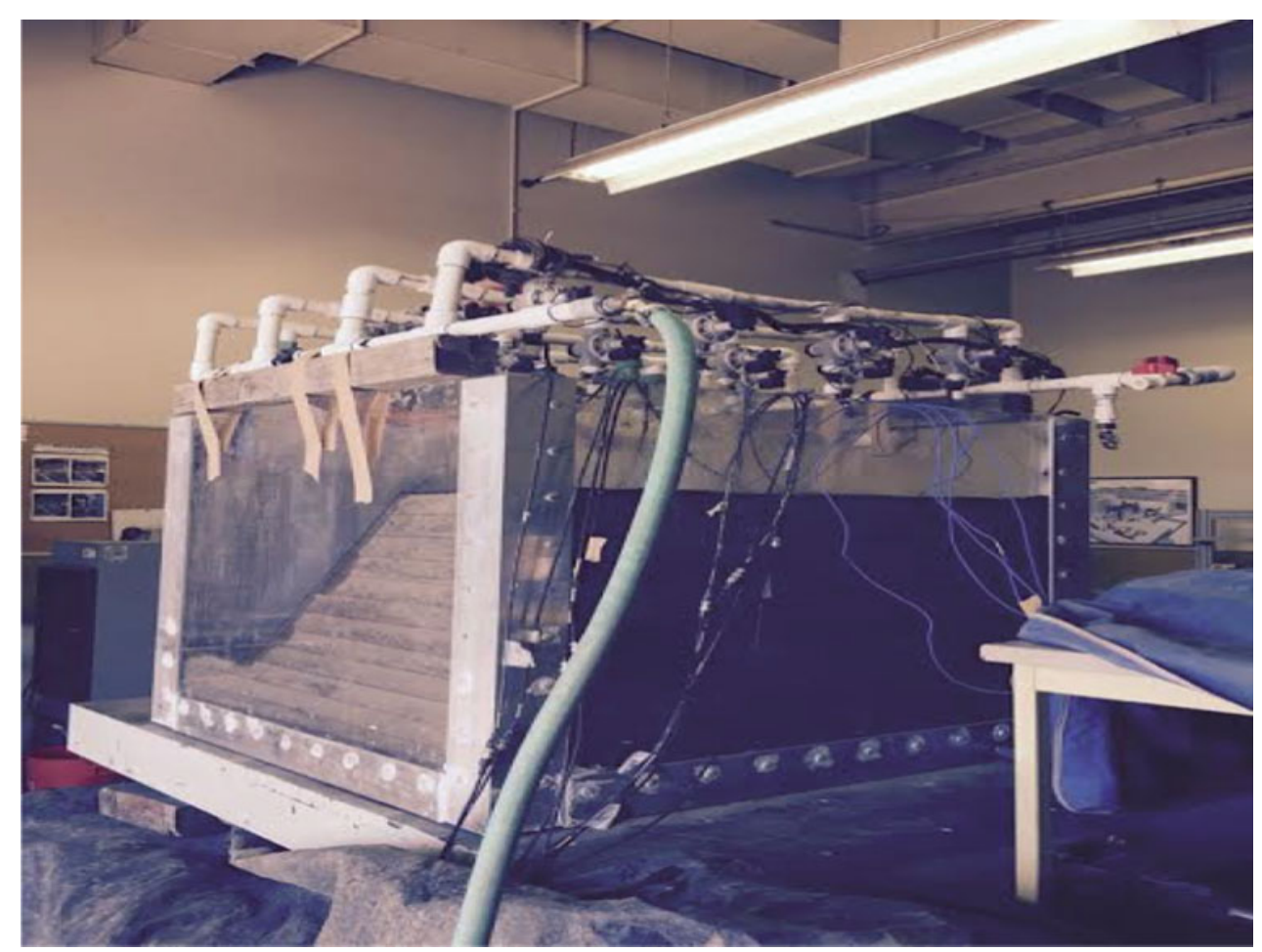

Fig. 5 Rain simulator system on slope model
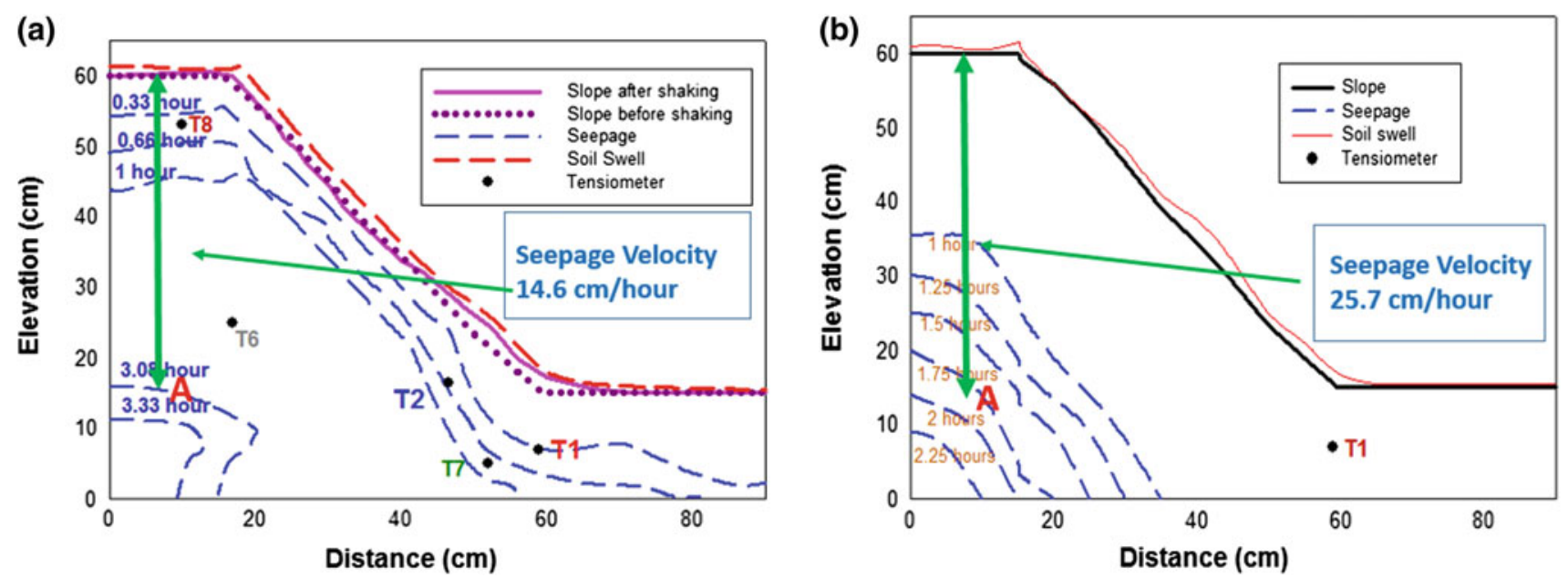

Fig. 6 Comparison of the wetting fronts and seepage velocities for slopes subjected to a post-earthquake rainfall and $\mathbf{b}$ rainfall without earthquake loading 

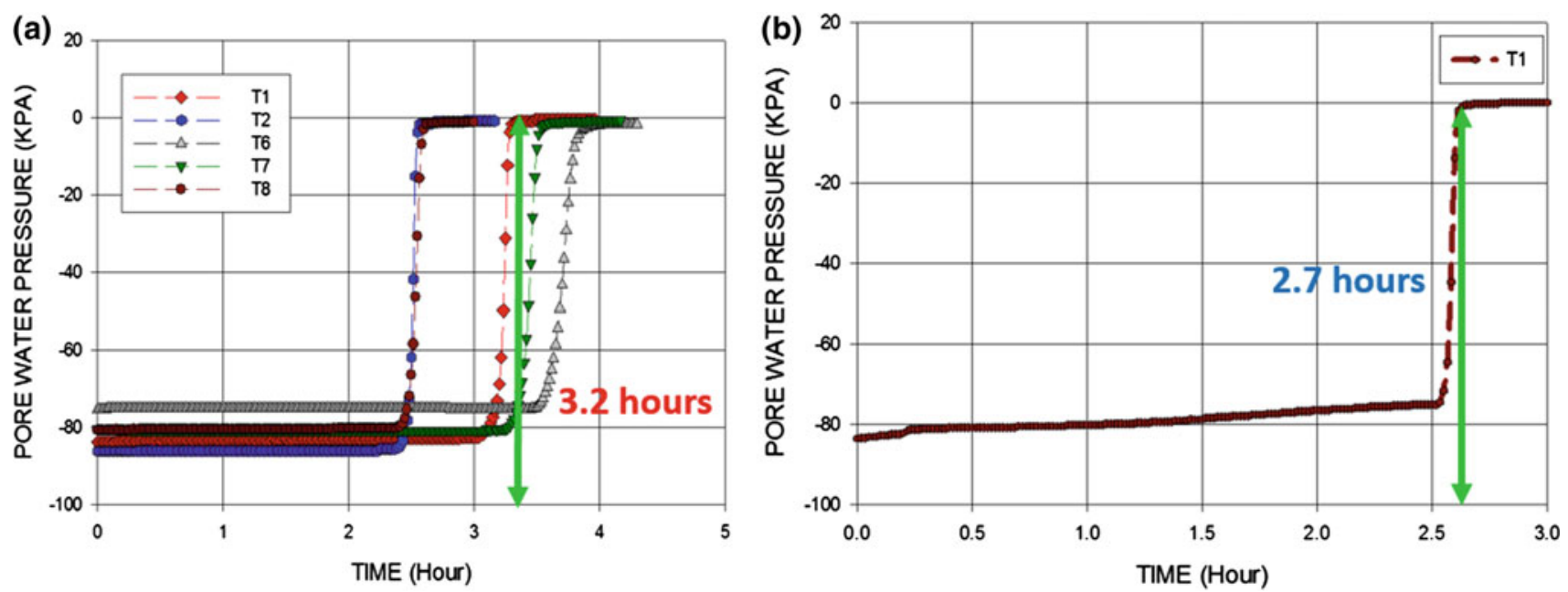

Fig. 7 Comparison of suction recorded at tensiometer 1 (T1) for slopes subjected to a post-earthquake rainfall and b rainfall without earthquake loading

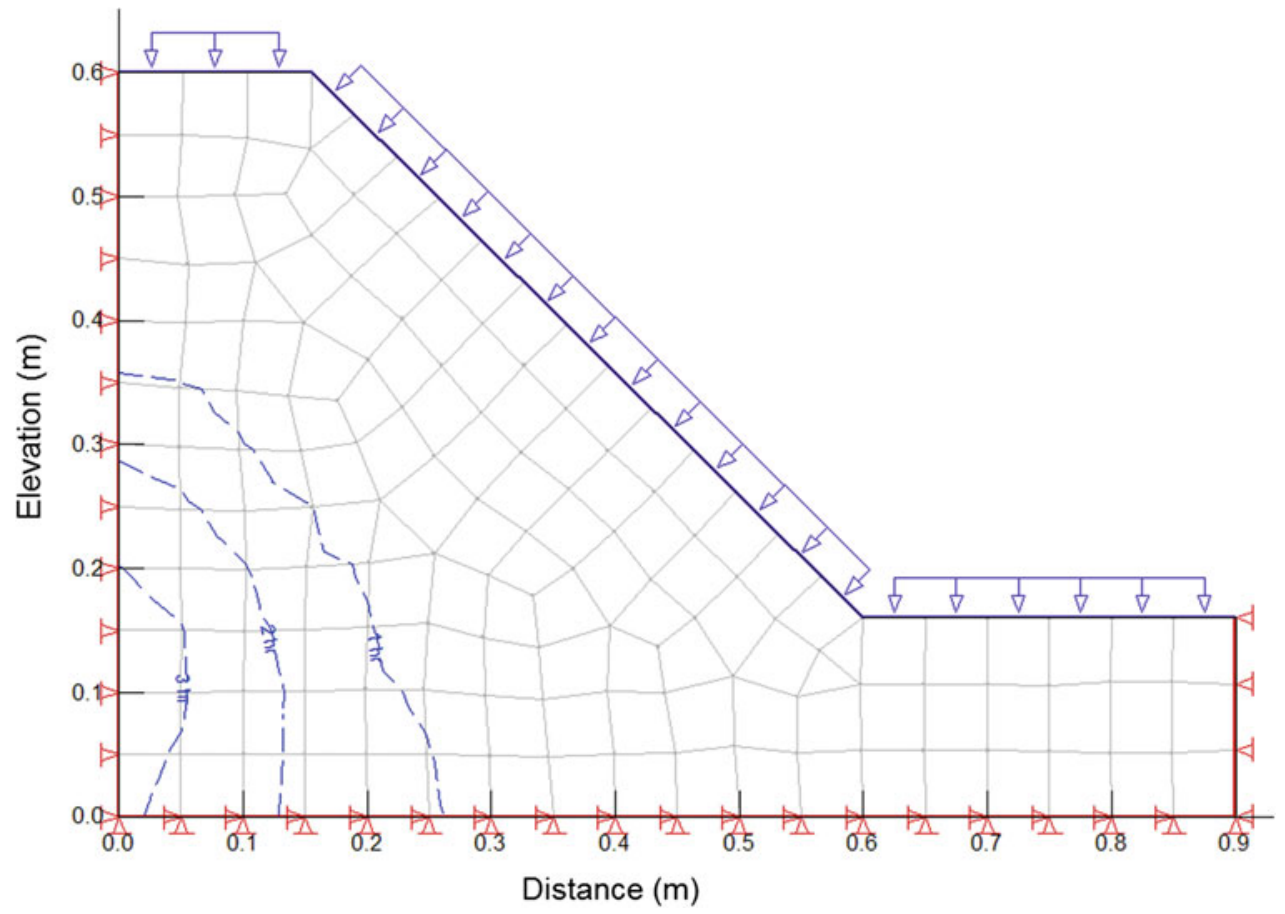

Fig. 8 Movement of the wetting front with time from numerical simulations 


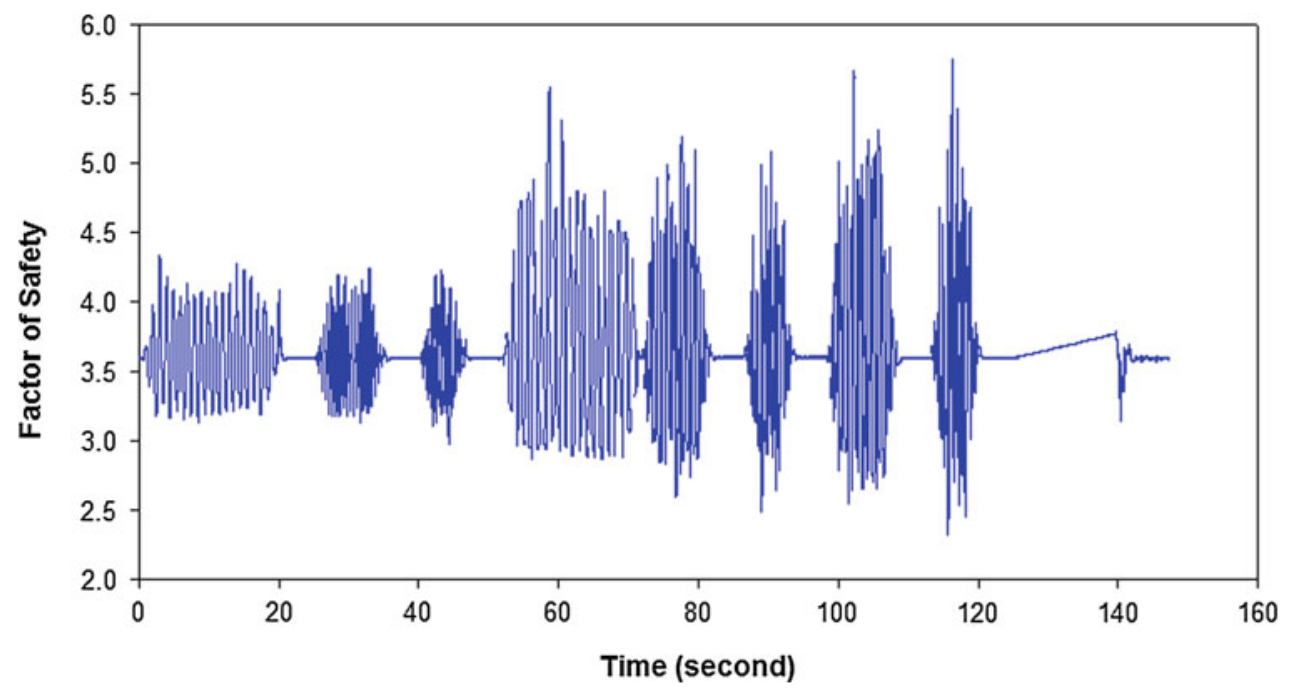

Fig. 9 Factor of safety computed from SLOPE/W during earthquake loading

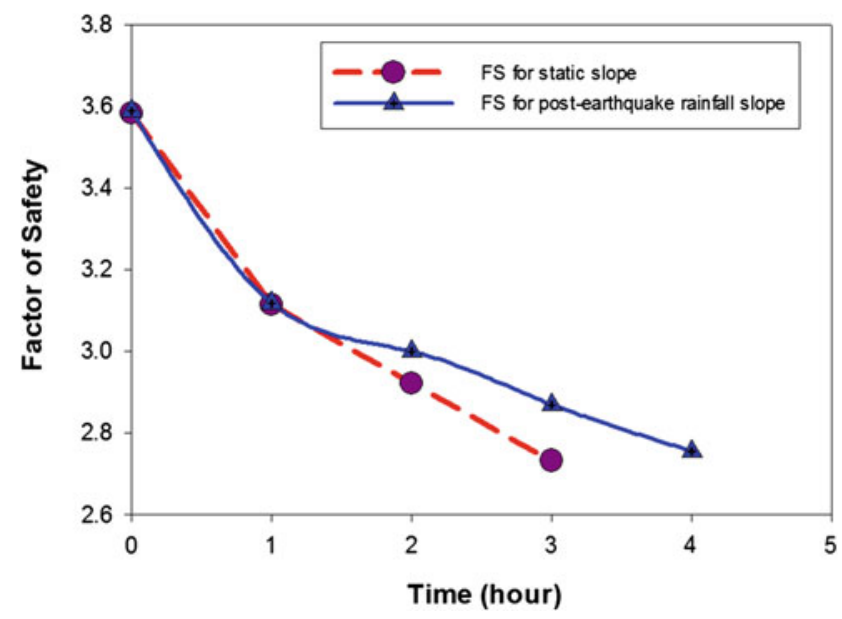

Fig. 10 Factor of safety computed from SLOPE/W in a slope subjected to rainfall following earthquake shaking and a slope subjected to rainfall without any earthquake loads

slope subjected to rainfall following earthquake shaking was higher than the slope subjected rainfall without any earthquake shaking. This can be attributed to the fact that the seepage velocity in the slope subjected to post-earthquake rainfall was lower than in the slope subjected to rainfall without earthquake loading.

\section{Conclusions}

In order to determine potential causes for the computed factors of safety, soil was collected from a landslide site and used to prepare the laboratory slope models in a Plexiglas container. The model slopes, instrumented with tensiometers and copper wires, were subjected to rainfall using a rain simulator system. A second model prepared to the same slope geometry and density was constructed on top of a shake table and subjected to a series of sinusoidal earthquake loading functions, as well as to the motion recorded from the 1995 Northridge Earthquake, before being subjected to rainfall at the same intensity as the previous model. The results showed that the slope subjected to post-earthquake rainfall required more time to become completely saturated and had a lower seepage velocity than the slope subjected to rainfall without earthquake shaking. The results suggest that the earthquake shaking was responsible for increasing the density of the slope material and thereby effectively reducing the permeability of the material, resulting in a more stable slope.

Acknowledgements The authors would like to thank the California State University, Fullerton Intramural Grant 3361, the Engage in STEM grant and the STEM ${ }^{2}$ grant for supporting students working on this project through stipends, as well as for funds required to purchase the materials and supplies necessary for this study.

\section{References}

ASTM D1557 (2012) Standard test method for laboratory compaction characteristics of soil using modified effort. Am Soc Test Mater

ASTM D3080 (2011) Standard test methods for direct shear test of soils under consolidated drained conditions. Am Soc Test Mater

ASTM D422 (2002) Standard test methods for particle-size analysis of soils. Am Soc Test Mater

ASTM D4318 (2010) Standard test methods for liquid limit, plastic limit, and plasticity index of soils. Am Soc Test Mater

ASTM D5084 (2016) Standard test methods for measurement of hydraulic conductivity of saturated porous materials using a flexible wall permeameter. Am Soc Test Mater

Collins BD, Znidarcic D (2004) Stability analyses of rainfall induced landslide. J Geotech Geoenvironmental Eng 130(4):362-372 
Dai FC, Xu C, Yao X, Xu L, Tu XB, Gong QM (2011) Spatial distribution of landslides triggered by the 2008 Ms 8.0 Wenchuan Earthquake, China. J Asian Earth Sci 40(4):883-895

Iverson RM, George DL, Allstadt K, Reid ME, Collins BD, Vallance JW, Schilling SP, Godt JW, Cannon CM, Magirl CS, Baum RL (2015) Landslide mobility and hazards: implications of the 2014 Oso disaster. Earth and Planet Sci Lett 412:197-208

Keaton JR, Wartman J, Anderson S, Benoît J, deLaChapelle J, Gilbert R, Montgomery DR (2014) The 22 March 2014 Oso landslide, Snohomish County, Washington, National science foundation geotechnical extreme events reconnaissance report

Khazai B, Sitar N (2004) Evaluation of factors controlling earthquake-induced landslides caused by Chi-Chi Earthquake and comparison with the Northridge and Loma Prieta events. Eng Geol 71(1-2):79-95

Kim J, Jeong S, Regueiro R (2012) Instability of partially saturated soil slopes due to alteration of rainfall pattern. Eng Geol 147:28-36

Ling H, Ling HI (2012) Centrifuge model simulations of rainfall-induced slope instability. J Geotechn Geoenvironmental Eng 138:1151-1157

Lu N, Wayllace A, Oh S (2012) Infiltrating-induced seasonally reactivated instability of a highway embankment near the Eisenhower tunnel, Colorado, USA. Eng Geol 162:22-32
Orense R, Shimona S, Maeda K, Towhata I (2004) Instrumented model slope failure due to water seepage. J Nat Disaster Sci 26 (1): $15-26$

Tiwari B, Ajmera B, Dhital S (2016) Photographic database and geospatial analyses of co-seismic landslides triggered by the main shock and aftershocks of the 2015 Gorkha earthquake. Report Submitted to the Department of Civil and Environmental Engineering, California State University, Fullerton

Tiwari B, Caballero S (2015) Experimental model of rainfall induced slope failure in compacted clays. Geotechn Spec Publ 256:12171226

Tiwari B, Tran D, Ajmera B, Woli H, Stapleton J (2016) Effect of pre and post earthquake rainfall events on deformation and stability of slopes. In: Proceedings of geotechnical and structural engineering congress

Tran D (2016) Effect of rainfall and seismic activities on compacted clay slopes having different void ratios and inclinations. Masters Thesis, Submitted to the Department of civil and environmental engineering, California State University, Fullerton

Wartman J, Dunham L, Tiwari B, Pradel D (2013) Landslides in Eastern Honshu induced by the 2011 off the pacific coast of Tohoku earthquake. Bull Seismol Soc Am 103(2b):1503-1521
Open Access This chapter is licensed under the terms of the Creative Commons Attribution 4.0 International License (http:// creativecommons.org/licenses/by/4.0/), which permits use, sharing, adaptation, distribution and reproduction in any medium or format, as long as you give appropriate credit to the original author(s) and the source, provide a link to the Creative Commons license and indicate if changes were made.
The images or other third party material in this chapter are included in the chapter's Creative Commons license, unless indicated otherwise in a credit line to the material. If material is not included in the chapter's Creative Commons license and your intended use is not permitted by statutory regulation or exceeds the permitted use, you will need to obtain permission directly from the copyright holder. 